Fanum

Sociológico
Forum Sociológico

Série II

$21 \mid 2011$

Transformação urbana

\title{
Da ética artificial e da moral de estado
}

\section{António Pedro Dores}

\section{(2) OpenEdition}

Journals

Edição electrónica

URL: https://journals.openedition.org/sociologico/484

DOI: 10.4000/sociologico.484

ISSN: 2182-7427

\section{Editora}

CICS.NOVA - Centro Interdisciplinar de Ciências Sociais da Universidade Nova de Lisboa

Edição impressa

Data de publição: 1 dezembro 2011

Paginação: 123-132

ISSN: 0872-8380

\section{Refêrencia eletrónica}

António Pedro Dores, «Da ética artificial e da moral de estado», Forum Sociológico [Online], 21 | 2011,

posto online no dia 05 setembro 2012, consultado o 30 março 2022. URL: http://

journals.openedition.org/sociologico/484 ; DOI: https://doi.org/10.4000/sociologico.484

Este documento foi criado de forma automática no dia 30 março 2022.

(c) CICS.NOVA 


\title{
Da ética artificial e da moral de estado
}

\author{
António Pedro Dores
}

O "cuidar de si" é um dos fundamentos éticos da modernidade, segundo Michel Foucault, 2004.

A Hermenêutica do Sujeito

"Não perguntem o que a América pode fazer por vocês. Perguntem antes o que vocês podem fazer pela América."

J. F. Kennedy

"The American Sociological Association recognizes the freedom of all peoples (...) and reaffirms the principles of ethical scientific conduct (...) respecting the rights, dignity, and worth of all peoples (...)", declaração de 12 de Agosto de 2009.

http://www.asanet.org/galleries/Governance/

Council\%20Statement\%20on\%20Human\%20Rights\%20\%28August\%202009\%29.pdf

1 Historicamente criou-se a esperança de a Revolução Francesa ter sido capaz de elevar as sociedades a formas igualitárias e pacíficas, mobilizando para tal as liberdades garantidas pelos direitos individuais. A Humanidade seria a sua herdeira e os Direitos Humanos a sua garantia. É, pois, com perplexidade que se assiste actualmente a políticas de troca de liberdade por segurança, desrespeito generalizado pelos contratos sociais constitucionalmente consagrados nos países do centro, à indução intencional do empobrecimento como política de expiação conduzida por uma classe política privilegiada e guardiã dos privilegiados, cf. Oborne (2008). Está criada uma sensação de derrocada civilizacional, em que à instabilidade crescente da vida dos mais desfavorecidos, oficialmente $23 \%$ dos europeus, se junta a instabilidade das classes médias e o enriquecimento continuado de uns poucos.

2 A sociologia, enquanto ciência, promoveu o sentimento de segurança nas virtudes pacifistas da civilização, por exemplo com Norbert Elias (1990), e da igualdade potencial dos indivíduos, atribuindo-se a si própria como uma das suas principais tarefas monitorar os níveis de desigualdade social, de que o último excelente exemplo é Wilkinson e Pickett (2009). Poderá, nas actuais circunstâncias, manter-se como mera observadora da concretização da modernidade? Não arrisca comportar-se como os teólogos aquando da queda de Constantinopla? Não será útil abrir oportunidades de 
emergência a formas de pensar a sociedade onde se dê prioridade a análises das violências vernáculas - como a procura de explicações para a permanência da guerra ou sobre a extensão gigantesca e geralmente ignorada da violência doméstica - e ao trabalho contínuo de produção intencional de desigualdades sociais - como seja o produzido nas penitenciárias em todo o mundo - em vez de reforçar a invisibilidade destes fenómenos com estratégias epistemológicas que não os desafiam?

Os limites da teoria social para a análise empírica das realidades sociais têm sido notados por diversos autores. Por exemplo, quando mostram a relevância actual das redes de computadores, como Manuel Castells (2003), ou do sistema prisional, como Loïc Wacquant (2000). Outros autores apontam as causas epistemológicas desses problemas, como Bruno Latour (2007) ou Philip Zimbardo (2007). O primeiro denuncia a autolimitação dos sociólogos quando chega a vez de observar os usos das tecnologias que saturam o nosso habitat, reduzindo o social às abstractas interacções entre humanos, sem mediações não humanas. Como se uma das características diferenciadoras da espécie humana não fosse a criação de utensílios. $O$ segundo, por seu lado, mostra como nos escapa a observação do efeito Lúcifer, mesmo quando - e sobretudo quando - somos seus criadores e fautores: os estados de espírito perversos são experimentalmente reproduzidos e institucionalmente induzidos nas pessoas como se fosse uma imposição moral. Eventualmente de boa consciência.

4 A teoria social fechou-se e fixou-se nas suas tarefas tradicionais. Em tempos de profunda transformação social, naturalmente, necessitará de se abrir a novas possibilidades e oportunidades para ser capaz de se actualizar e acompanhar as mudanças no mundo. Esse trabalho inclui ultrapassar repugnâncias disciplinarmente desenvolvidas, nomeadamente contra tecnologia e contra a observação das perversidades promovidas e utilizadas pelas instituições modernas.

\section{A evolução do papel modernizador da sociologia}

5 Apesar da ideologia dos vencedores individualizados, herdeira das sagas heróicas adaptadas à vida e sucessos burgueses e empresariais, a coesão dos grupos sociais nunca deixou de ser e continua a ser decisiva. Isso foi apontado por Tocqueville, na sua A Democracia na América da primeira parte do século XIX, como nos países mais desenvolvidos na segunda metade do século XX por Fukuyama (1996). Formas de coesão cuja eficácia não pode ser explicada no quadro ideológico individualista e, por isso, são alvo de teorias da conspiração - referência à existência de seitas e sociedades secretas descritas como maléficas e largos poderes de influência, de que a globalização seria a concretização intencional -, de teorias securitárias - análise de riscos e classificação de campos de intervenção prioritária, com fins punitivos e terapêuticos ou preventivos sobretudo contra eventuais reacções da populaça -, de teorias sobre relações internacionais e estratégicas - que tratam das alianças entre Estados para fazerem a diplomacia e a guerra. Tanto a nível internacional, das classes dominantes e das classes populares, a ideologia da sociedade moderna como sociedade de indivíduos expulsa do campo da sociologia a questão da formação de solidariedades, espontâneas e organizadas, para disciplinas como as relações internacionais, a história, a criminologia, a ciência política, reduzindo o campo de intervenção sociológico a um território especial e exíguo, dentro das paredes idealizadas do nacionalismo metodológico ${ }^{1}$. 
6 Da proposta imperialista do positivismo de fazer da sociologia o lugar da confluência de todas as ciências, resta hoje a realidade da dispersão hiperespecializada do campo das ciências sociais, divididas em disciplinas e subdisciplinas com pouco ou nenhum contacto entre $\mathrm{si}^{2}$.

7 A sociedade actual aparece representada por um magma de fenómenos sociais erráticos, orientados por mercados abertos à participação de indivíduos pacificados, civilizados, autocontrolados, competitivos, mas cada vez menos livres e menos iguais entre si, ao contrário do que era a promessa modernizadora, cf. Sennet (2006).

8 Enquanto houve esperança de a modernidade significar progresso, isto é, mais liberdade e mais igualdade, o papel da sociologia poderia ser o de ajudar a encaminhar para os canais de integração social institucionalmente desenhados o magma social, anotando as características pessoais e sociais dos integrados e dos excluídos como causas auto-referenciadas da sua integração e da sua exclusão. Quando essa esperança se perde, cf. Young (1999), à manutenção das mesmas práticas sociológicas corresponderão significados sociais distintos. Para que a sociologia continue a pugnar pelos valores tradicionais da modernidade terá de rever e actualizar o seu lugar no quadro das disciplinas científicas e na sua relação com as instituições e as sociedades.

\section{Os direitos humanos são contraditórios com o capitalismo ${ }^{3}$}

9 Os direitos humanos surgiram nos anos mais recentes como um novo campo de especialidade da sociologia. Acompanhou a viragem das atenções dos activistas desta área para o que se estava a passar no Ocidente.

o movimento dos direitos humanos iniciou-se como uma forma de expandir o exemplo das sociedades ocidentais ao resto do mundo. A partir dos anos 90 , sentiu necessidade de virar a sua atenção também para a degradação moral das instituições nos países ocidentais.

11 Tomemos como caso de reflexão a renovação do interesse pelos estudos prisionais, descoberto o gulag ocidental, nos EUA, cf. Christie (2000). Loïc Wacquant (2002) e Michelle Alexander (2010) apresentam o hipermoderno sistema prisional, altamente tecnológico e competitivo e em parte privatizado, como continuidade das instituições escravocrata e segregacionista. De facto, as explicações individualizantes não explicam nem o aumento exponencial do número de presos (quase 10 vezes nas três últimas décadas) nem a percentagem desproporcionada de afro-americanos presos ${ }^{4}$. Mais do que um problema de anomia episódica a recuperar com o tempo, o que houve no país mais moderno do mundo foi a organização de uma vontade social de discriminação traduzida sistematicamente em intenções policiais e judiciais coordenadas pelas classes dominantes para excluírem e, ao mesmo tempo, se guardarem das potenciais reacções dos excluídos, como propõe a noção de sociedade penitenciária de Wacquant (2000).

As práticas repressivas modernas, tradicional e institucionalmente apresentadas como reactivas para manutenção da ordem e da justiça democráticas, sofreram uma profunda alteração nas últimas décadas. Trata-se hoje de reduzir riscos. No campo da criminalidade, cf. David Garland (2001), institucionaliza-se a finalidade preventiva de excluir do convívio social as pessoas com perfil de risco, escolhidas entre as populações 
historicamente estigmatizadas, nomeadamente através de penas de morte, de prisão perpétua, de inibição de direitos políticos mesmo após o cumprimento de pena.

Este radicalismo aplica-se de forma invertida no campo dos negócios, onde a tolerância às práticas ilegais é endémica, cf. Woodiwiss (2005). 0 que se tornou evidente durante a crise financeira de $2007 / 8$, sem que nem o gulag para os excluídos nem a impunidade para os dominantes tenha mudado ou esteja previsivelmente a mudar.

Em Portugal, além da justiça para pobres e para ricos, da inoperância da luta contra a corrupção, das dificuldades da luta contra os crimes de colarinho branco, o sistema penitenciário, embora longe de se poder comprar com o dos EUA, está outra vez em processo de sobrelotação. As estimativas apontam para $50 \%$ de presos serem filhos de outros presos, $60 \%$ de presos deram entrada na prisão por mais de uma vez ${ }^{5}, 80 \%$ de presos foram institucionalizados pela primeira vez antes dos 16 anos em instituições de acolhimento de menores ${ }^{6}$. Semelhantemente ao que ocorre nos EUA, fica-se com a impressão de ser apenas uma fracção muito específica dos grupos sociais excluídos que é atingida pelo encarceramento. Também por cá, apesar das grandes diferenças, a selecção institucional das populações-alvo para fins de encarceramento pode ser tão importante que o comportamento individual só terá um peso relativo como causa eficaz do encarceramento.

No dizer dos especialistas, o sistema penitenciário como forma de reinserção social fracassou. E o reconhecimento desse fracasso pode ser o seu sucesso. Alimenta-se de reincidentes produzidos desde pequenos, os chamados pré-delinquentes, pelos serviços sociais do Estado. $\mathrm{O}$ que transforma as portas das prisões num sistema giratório. Como perguntaram Jakobs e Meliá (2003), não será preferível separar o direito penal em três? Um para os empresários, que funcionaria no sentido moderno que lhe deu Durkheim: sem penas de prisão e apenas com multas. Outro para os cidadãos comuns, que poderiam ser objecto de penas de prisão, caso cometessem crimes. Um terceiro, sobretudo para os estrangeiros e terroristas, considerados inimigos, a quem o direito não se aplica, como acontece em Guantánamo, nas prisões de tortura secretas pelo mundo fora ou nos centros de detenção de sem-papéis ${ }^{7}$.

16 Poderá a sociologia permanecer neutral face à divisão manu militari das sociedades modernas em sociedades de castas? Pode continuar-se a pensar que a força das armas está sob controlo civil e os interesses económicos das classes dominantes são compagináveis com os interesses económicos das outras classes, sob a tutela de cada Estado Nacional? Está o Ocidente em condições objectivas de manter o seu próprio respeito pela democracia, pelo estado de direito e pelos direitos humanos?

\section{Mudança de paradigma}

17 A emergência de um sentimento social de fim de ciclo é acompanhada pelos economistas. Disputam publicamente o valor das teorias neoclássicas, malthusianas, keynesianas, marxistas entre outras, e descobrem como as escolas de economia foram transformadas nas últimas décadas em centros difusores dos dogmas neoclássicos. No campo da sociologia, os nacionalismos ou individualismos metodológicos, institucionalismos ou realismos críticos, estruturalismos ou interaccionismos simbólicos não provocam qualquer eco mundano. Com a crítica do imperialismo sociológico, a teoria social deve submeter-se a um lugar cognitivo subalterno no concerto científico? Ou, ao contrário, deve procurar evoluir afirmando as suas 
potencialidades, nomeadamente quando se trata de ajudar a organizar as consciências leigas, especialmente numa altura tão crítica como aquela que a Europa atravessa?

Se há momentos propícios a mudanças de paradigma científico, cf. Khun (1970), nas ciências em geral e nas ciências sociais em especial, esses são quando a instabilidade social é mais evidente e sentida. Balizar cognitivamente essa transformação naturalmente induzida pela vida social exige abertura de espírito e reconhecimento dos limites próprios dos paradigmas anteriores, a superar.

Os sociólogos, por hipótese, podem estar acantonados num mundo social idealizado e fechado em si mesmo, excluídos da política, da economia - aliados sobretudo das pragmáticas administrativistas próprias do Estado Social - bem como auto-excluídos da observação das violências institucionais ${ }^{8} \mathrm{e}$ das formas de promover socialmente sentimentos de justiça ${ }^{9}$.

O grosso da sociologia como que se refugiou dentro das instituições do estado moderno e aí se burocratizou, em especialidades segundo as oportunidades, perdendo de vista os contextos mais amplos onde se jogam as transformações sociais.

21 O estudo das instituições exige previamente um melhor entendimento das respectivas finalidades, nomeadamente a melhor interpretação do que sejam os seus estatutos expressos à luz das dinâmicas sociais e do espírito de promoção, resistência ou marginalidade institucionalmente adoptado em relação a elas. Podemos estar a viver num tempo onde aquilo que se diz e se pensa, anomicamente, corresponde àquilo que se pensou poderem ser bons propósitos, quando na prática o que valem são outros propósitos bem distintos e que dispensam a explicitação dos respectivos objectivos. A ter em conta a emergência dos debates sobre mentiras, crimes e corrupção na vida política, o que parece interessar mais actualmente são as estratégias de encobrimento e não as de clarificação e esclarecimento. Estas últimas continuarão a ser prosseguidas pela ciência e, portanto, pelos sociólogos. Mas não se devem deixar iludir pelo não dito, pelo não visto, pelo que está escondido, tanto ao nível quotidiano como ao nível do poder.

Quadro 1 通 Organizar o sistema AGIL dentro da tipologia de níveis sociais

\begin{tabular}{|l|l|l|l|l|}
\hline & Economia & Política & Sociedade & Cultura \\
\hline Nível de cima & Sistema-mundo & Cibernética & Inteligência social & Espiritualidade \\
\hline Nível do meio & Mercado & Instituições & Burocracia & Profissões \\
\hline Nível de baixo & Quotidiano & Tecno-estrutura & Família & Bem-estar \\
\hline
\end{tabular}

22 A hipótese avançada por Durkheim de a divisão de trabalho social, e portanto a economia e a política (bem como a aplicação da justiça correspondente), ser a concretização de um tipo de consciência colectiva etérea (não consciente) anteriormente adoptado continua a ser estudada nas introduções à sociologia. Mas não está a ser considerada pelos sociólogos para pensar a transformação actual.

23 A exploração de algumas hipóteses abandonadas pelas orientações dominantes da sociologia contemporânea é fonte de inspiração para a tarefa, necessariamente voluntarista, de adaptar - transformando - a sociologia aos tempos de mudança 
profunda em que estaremos embrenhados nos próximos anos. Por exemplo, a substituição das dimensões funcionalistas - economia, política, cultura e social - por outras focadas nos movimentos sociais - o capitalismo, o industrialismo, o controlo social e as relações bélicas internacionais - proposta por Giddens (1985); ou a extensão do conceito de sociedade às estruturas e recursos tecnológicos que caracterizam cada sociedade - proposta por Latour (2007); ou a extensão cibernética das relações entre a vida e as máquinas em inteligência colectiva - proposta por Bateson (1987) e por Minsky (1985).

Numa fórmula extremamente sintética proporemos sujeitar as dimensões sociais $\mathrm{AGIL}^{10}$, verticalmente justapostas em sistema, à prioridade de referências horizontais a três tipos de níveis de realidade: os níveis do meio (similares àqueles utilizados vulgarmente pela sociologia, em que só factos sociais podem explicar factos sociais, na expressão de Durkheim que faz apelo ao fechamento disciplinar em que efectivamente temos em grande parte vivido); os níveis de baixo, que ligam o social puro, digamos assim, com realidades mais vernáculas (como por exemplo o quotidiano e a família, instituição muito diferente das outras, mas associada a elas à falta de melhor solução); os níveis de cima, que ligam o social puro à imponderabilidade daquilo que é etéreo (por exemplo, a espiritualidade tratada por Durkheim (2002) como fundamento da teoria social e da solidariedade - nomeadamente a distinção radical do sagrado e do profano - na prática remetido para a pouco influente subdisciplina da sociologia das religiões).

Tal como no sistema AGIL, os três tipos de nível social são aplicáveis a qualquer objecto, a qualquer nível de realidade. 0 nível de cima abre o objecto de estudo a realidades superiores, no sentido em que o Direito se abre aos valores. O nível do meio fecha em sistema o alvo da nossa atenção. O nível inferior abre o foco da nossa atenção a realidades inferiores, vernáculas, como as necessidades biológicas da existência.

Ao profano corresponde o nível inferior. Aquele que nos relaciona com a nossa herança evolutiva - a terra, a água, o ar, os outros seres vivos. Ao sagrado corresponde o nível superior. Aquele que nos relaciona com as nossas ocupações pós-materialistas. A modernização aparece como uma tenaz capaz de apartar um do outro estes dois níveis, tornando-os irreais. A normalização da vida moderna, o seu carácter desencantado, para usar a expressão weberiana, resulta do hiperdesenvolvimento do nível intermédio, institucionalmente construído e mantido. Fecha-se sobre si próprio, criando e delimitando ambientes cada vez mais complexos, especializados e estanques. Modernização que também fechou num espaço demasiado limitado a teoria social e com o qual nos cabe romper.

Do mesmo modo que as cidades, entretanto, se tornaram metrópoles, feitas de e imaginadas como redes de condomínios fechados em mancha de óleo e interstícios de exclusão em luta por uma ascensão social ou simplesmente pela sobrevivência, também as ciências sociais perderam a sua originária aspiração unitária e se metamorfosearam em disciplinas e especialidades, banhadas num magma de gente formada e respeitosa (mais do que utilizadora) dos saberes assim produzidos. Saberes isolados entre si e isolados das populações, com as dificuldades inerentes de lhes acompanhar as frustrações e as esperanças.

28 A política e a economia estão a falhar. Qual é ou pode ser o papel da sociedade, nesta conjuntura? A democracia, o estado de direito e o respeito pelos direitos humanos devem ser abandonados, por não serem mais suportáveis pelas instituições e pela 
economia que as alimenta? Ou serão as instituições e a economia que devem ser alteradas para que os direitos humanos sejam respeitados?

\section{A justiça como instrumento de harmonização}

A sociedade humana tem características herdadas evolutivamente de outras espécies e, ao mesmo tempo, características que lhe são próprias, como o raramente citado mimetismo proposto por Tarde (1993), confirmado pelos biólogos que descobriram uma quantidade de células fusiformes muito superior nas pessoas do que nos outros primatas. A sociedade humana, antes de ser objecto de conhecimento científico e de investimento de intenções de poder próprios da sociedade ocidental individualista actual, é uma mediação entre a evolução da vida, de que somos como espécie um traço (e como indivíduos meros espécimes) e o infinitamente grande que nos acolhe eternamente (para vidas tão exíguas quanto as nossas).

A esta luz, a improvável mas desejável harmonização dos diferentes níveis de realidade pode ser apontada como a tarefa mais urgente da humanidade actual. A sociedade harmoniosa depende dela própria, bem como das mediações que venham a ocorrer com níveis superiores e inferiores - verdade equiparável a um axioma matemático que propomos passar a ser usado pelas ciências sociais, abertas entre si e a outros conhecimentos, à procura da sabedoria que melhor possa servir a humanidade.

Convém, porém, distinguir nível superior de realidade social - como o carácter nacional ou o tipo de solidariedade vigente - do que sejam os poderes instituídos. Estes últimos, afinal, por muito poderosos que sejam - e são - dependem sempre, para o seu funcionamento, de mínimos de legitimidade social que dependem, na prática, das sociedades e dos seus comportamentos potencialmente instáveis.

O estudo da normalidade e do moderno como modelo ideal foi consagrado pelo estrutural funcionalismo. A crítica deste modo de fazer sociologia não tem sido suficientemente apta para romper com a visão horizontal e burocrática do papel do sociólogo em sociedade. Provavelmente menos por falta de profundidade nas críticas do que por impossibilidade de organizar uma alternativa epistemológica face à intensificação das patrulhas de bons costumes nas fronteiras disciplinares $\mathrm{e}$ subdisciplinares. Com um impulso exterior, promovido pelas mudanças sociais em curso, a sociologia será, mais uma vez, obrigada a reposicionar-se.

A justiça, na perspectiva de harmonização, deixará de ser olhada meramente como uma instituição horizontal entre outras, com o seu prestígio próprio, as suas próprias cultura e economia política, fora do quadro de difusas mas eficazes e potentes relações de poder ao "nível de cima". A justiça poderá passar a ser reconhecida como a principal estratégia de humanização e controlo das tecnologias, cf. Supiot (2002), mobilizada para descobrir os tipos de consciência social actuais, cf. Durkheim (1984). A justiça é, para as pessoas, ao mesmo tempo um resultado e um instrumento de harmonização social com a vida e o cosmos, muito para além, portanto, do funcionamento mundano das instituições judiciais e repressivas.

34 A consciência colectiva, como o conhecimento em geral, produz tanto factos quanto segredos sociais, ao mesmo tempo reconhecidos e desconhecidos das pessoas, emocionais e racionais, que a sociologia está habituada a mostrar e revelar (e também a ignorar ou mesmo esconder). A concretização da justiça comum (i.e., autorizar a 
circulação da verdade - oficial - e desvalorizar aquilo que se lhe oponha), como satisfação das necessidades de harmonização das pessoas, grupos e sociedades entre si, foi institucionalmente cooptada por uma elite aristocratizada e corporativamente defendida ${ }^{11}$. Através da burocratização, que se tornou característica das sociedades modernas (burocratização que também atingiu a sociologia encarcerando-a nos tipos de "níveis do meio"), a justiça apresenta-se, na prática, tão distante quanto pode das partes em litígio, fazendo por esconder as suas próprias inclinações, seja através do segredo de justiça no processo, através do segredo de Estado ou através de obscuras linguagens disciplinares. Na prática, a justiça serve os poderosos do momento (em caso de democracia, as maiorias) e coopera com os outros poderes de Estado, dos quais de resto depende. Fá-lo, por exemplo, reduzindo a casos particulares, irrepetíveis e sobretudo isolados, cada situação que lhe seja presente, nomeadamente: a) mostrandose incapaz de relevar as diferenças de poder económico, político e cultural dos arguidos; b) afastando as vítimas do conflito; e c) actualizando sistematicamente o poder do Estado, através das decisões judiciais apoiadas nas polícias, nos cárceres e nas conjunturas políticas do momento.

(Na prática observam-se duas justiças: a que é aplicada aos pobres e a que é aplicada aos ricos, espécie de distorção socialmente induzida independentemente das intenções dos magistrados e da normatividade a favor da igualdade de tratamento. Mais de dois séculos depois de a paixão democrática dos povos europeus ter feito do Ocidente uma referência moral para todos os seres humanos, em nome da liberdade e da igualdade e dos instrumentos doutrinários e económicos para fazer valer tais valores, será tempo de se verificar como a liberdade continua a ser apenas para alguns e a fé na igualdade está a esmorecer.)

Aqui chegados, cabe aos sociólogos interessados na modernização prática das sociedades deitar a cabeça de fora do seu campo habitual de actuação e, por exemplo, juntarem-se aos esforços dos que pugnam pelos Direitos Humanos, virarem-se para o interior dos países mais modernos - contra a guerra, a tortura, as prisões extrajudiciais, a injustiça e o secretismo que recobre tais práticas. Isso implica um repúdio mais enérgico da ideia do progresso teleológico moral automático a partir da evolução da civilização ocidental, bem como da alegada neutralidade que caracterizaria a ciência burocrática normalizada, que mais não é do que a forma de auto-enquistamento defensivo contra os incómodos que sempre implica a procura da verdade.

\section{A justiça como instrumento de harmonização identitária, pessoal e nacional}

37 A justiça é um exemplo de expressão polissémica que tanto representa a) um estado ideal de harmonia social, a humanidade, como b) o reconhecimento da vernácula instabilidade moral da vida, nomeadamente o desejo de vingança. Entre uma e outra justiças há mediações, como a de poderes divinos, estatais, paternais ou outros. Entre a esperança de harmonia social e as necessidades de afirmação identitária há contradições insanáveis, há impulsos irresistíveis, há decisões inevitáveis e há, também, recurso a formas especiais de mediação e de estabilização, através da mobilização de níveis superiores da realidade. situação vigente e, ao mesmo tempo, incapaz de não reagir. Perante o dilema, para 
evitar as consequências geralmente violentas da sua própria neutralização enquanto agente social (ou da neutralização da alegada causa do mal-estar), porque se tratará em breve de um problema que afectará gente actualmente alheia à questão, em nome da harmonia social, apela-se ao sentido comum de justiça e, nesse sentido, às formas institucionalizadas encarregues de o determinar e anunciar.

Tomemos o caso de José Luís Jorge dos Santos, cidadão português de origem norteamericana capturado pela polícia portuguesa em Sintra, 40 anos depois de ter fugido de uma penitenciária norte-americana. O Estado norte-americano reclamou junto das autoridades portuguesas a sua extradição para acabar de cumprir a pena a que tinha sido condenado. A justiça portuguesa negou a extradição, sobretudo com base no reconhecimento da legitimidade da nacionalidade portuguesa e, portanto, na ilegitimidade de entregar cidadãos nacionais a países terceiros.

o debate público centrou-se sobre a prescrição das penas, mesmo quando se trate de crimes graves. Na perspectiva de a finalidade da justiça penal ser a reintegração social dos condenados, a prescrição justifica-se a partir do tempo em que a penalização do crime deixará presumivelmente de ter efeitos sociais. Porém, se a finalidade da justiça for a incapacitação dos condenados, como passou a ser o caso nos EUA e na GrãBretanha nas últimas décadas, segundo David Garland (2001), quem comete um crime grave deve ser definitivamente afastado da sociedade. E, coerentemente, nos EUA não há prescrição de crimes: os seus autores são criminalmente responsabilizáveis a todo o tempo.

o caso envolveu o assassínio de um veterano de guerra, dono de uma estação de gasolina, durante um assalto em que o jovem George Wright participou. Mas envolveu também a segregação racial que se vivia então nos EUA, a negociação judicial prévia ao julgamento entre um advogado oficioso e o Ministério Público sobre a pena a aplicar nomeadamente a atribuição da autoria do homicídio a George em troca do afastamento da perspectiva da pena de morte - e a luta pelos direitos cívicos dos afro-americanos em que George acabou por se envolver na prisão. Foi a organização militante que lhe facilitou a fuga da cadeia e que lhe proporcionou a fuga para África - através do desvio de um avião.

Quarenta anos depois, nos EUA, os outros envolvidos na morte do gasolineiro estavam em liberdade, após cumprimento das respectivas penas. Na Europa, o resto do grupo que desviou o avião estava também em liberdade - embora sem possibilidade de visitar os EUA - após cumprir penas impostas por tribunais europeus. $O$ único que escapou ao cumprimento de pena completo foi George, aliás Jorge.

43 A filha do assassinado faz campanha pela extradição por entender que assim se faria justiça. 0 cumprimento do resto da pena por parte de Jorge, afirmou, seria bom para ela própria e para a sua família, como também para a própria família do afro-americano nacionalizado português.

Este exemplo mostra como o nível do meio da análise social, no qual a sociologia actual está autolimitada, é apenas um dos níveis a considerar. A este nível o processo burocratiza-se, especializa-se e torna-se mesmo opaco para o leigo. Como diria Max Weber, a gaiola de ferro da burocracia judiciária, por um lado, assegura a racionalidade dos processos, no sentido mais processual que substantivo; por outro lado, formaria uma caixa preta obscura para o observador não especializado e, na verdade, para qualquer observador. 
Está em causa, a nível superior de análise, se os condenados devem ser excluídos da sociedade ou se se devem fazer esforços para os integrar.

Ao nível inferior pode apreciar-se como a filha do assassinado alega ter vivido 40 anos a angústia da morte violenta do pai e que a prisão de Jorge a satisfez. E, por isso, continua a luta pela sua extradição para os EUA. Ao mesmo nível vernáculo podemos apreciar o que significou para Jorge viver um segredo, enquanto construía uma família saudável, tendo de sofrer a revelação pública da história intencionalmente esquecida (e temida) na condição de recluso.

Cada uma das partes viveu o tempo dos processos judiciais em que se litigou de forma oposta, como é de esperar pelo respectivo papel no processo. O fim dos processos judiciais pode não satisfazer nenhuma das partes, por razões distintas. E o processo pode não ser um fecho do assunto, já que, neste caso, o empenhamento dos EUA, como única superpotência global, decorre de políticas securitárias que actuam para além dos julgamentos judiciários, a um nível superior.

A análise dos níveis superiores do caso mostram como os conceitos institucionais de justiça vigentes em Portugal limitam no tempo a vigência politicamente legítima do sentimento de vingança, digamos assim. Em contraste com o que ocorre nos EUA, onde tal tipo de sentimento tem reconhecimento judicial permanente. É sobre as entranhas da natureza humana que se constroem as práticas judiciais, muito diferentes entre si.

O desenvolvimento da análise do nível inferior revela-nos a importância e a influência directa do nível superior de análise, que na prática atravessa, de cima para baixo, toda a questão (como a biopolítica atravessa a mesma questão, mas em sentido contrário). 0 conceito de justiça punitiva norte-americano é não apenas incapacitante para quem esteja a cumprir pena. Caracteriza-se ainda por ser discriminatório não só dentro dos EUA mas também fora do seu território, nomeadamente pelo facto de sistematicamente o governo federal ratificar os tratados internacionais relativos aos direitos humanos com a salvaguarda de em território norte-americano e para julgar cidadãos norteamericanos em qualquer parte do mundo serem os tribunais norte-americanos os únicos competentes, sem reconhecimento de nenhuma tutela judicial internacional.

Aquilo que os EUA jamais admitiriam para um cidadão seu, reclamaram a Portugal. Neste caso, embora nunca fosse claramente explicitado, dadas as relações de forte dependência entre Portugal e os EUA, esteve em causa a própria dignidade da identidade nacional portuguesa. Foi, sem dúvida, com alívio que os comentadores portugueses unanimemente declararam como boa a decisão dos tribunais portugueses de negarem o pedido de extradição.

51 Precisamente a mesma dependência entre estados faz com que a filha do assassinado mantenha a esperança e a campanha contra Jorge e este, por sua vez, se mantenha inseguro, na expectativa de onde possa vir o próximo golpe, incluindo por meios extralegais que têm caracterizado a política externa norte-americana.

Na verdade, a sociologia pode tomar cada caso judicial no estrito âmbito reconhecido pelo processo - neste caso, um pedido de extradição para cumprir pena interrompida por fuga - ou dar-se a si própria o direito de escolher o escopo da sua própria análise sociológica. Se o fizer poderá dar-se conta de muitos e importantes fenómenos sociais sem os quais o processo jamais teria sido construído, mas que estão fora do âmbito do processo, de modo intencional. 
Neste caso concreto, seria incompreensível a sanha persecutória sem se saber como o Estado norte-americano tratou policialmente, de forma clandestina, a organização política dos negros no tempo dos movimentos dos direitos civis. E como continua a prosseguir políticas herdeiras das de então ${ }^{12}$. No quadro das quais cabem as despesas feitas pelo Estado norte-americano para punir Jorge dos Santos. Assunto que se mantém tabu, mesmo quando é expressamente referido pelos media ${ }^{13}$.

Do mesmo modo que no tempo de Salazar a censura impunha, a nível nacional, formas de referência a assuntos tabu de forma oblíqua - ficou famosa, por exemplo, a História da Ida à Guerra de Raul Solnado -, o poder da actual superpotência impõe autocensura na sua área de influência política, incluindo Portugal.

o processo foi desenhado para ter sucesso, por parte de quem o promoveu. Quereriam apresentar serviço no âmbito de uma velha guerra, afinal tão actual que se pode resumir, de forma brutal, em meter pretos na cadeia, cf. Wacquant e Alexander já citados. Anunciava-se uma decisão em quinze dias e intimidou-se os defensores (assim se queixaram os próprios publicamente). Não se falou da pendência de um processo judicial contra o desvio do avião, que poderia valer a pena de morte - outro tipo de prática intolerável à luz da ordem jurídica portuguesa. Na prática, porém, a decisão veio a ser desfavorável à extradição e, nessa circunstância, entraram em campo as pressões políticas de um movimento de cidadãos norte-americanos, encabeçados por um senador, para reclamar do governo português a extradição.

Isto é, quando Jorge dos Santos declarou que Obama está a esquecer-se de que foi a luta de gente como ele próprio que possibilitou e facilitou o seu sucesso político pessoal, quando um simples arguido se dirige como um igual, como um ancestral, como um ser moralmente superior ao homem mais poderoso do mundo, o que está em causa não é nem a economia, nem a política, nem a cultura. 0 que está em causa é a denúncia pública da dessincronização, a distorção, da falta de harmonia entre os níveis superiores e inferiores da vida no Ocidente: a continuação de novas versões da escravatura no porão, as festas multiculturais na piscina e nos salões, e a ignorância intimidada de cair borda fora - caso insista em tomar conhecimento das imoralidades -, própria das classes intermédias e das instituições.

\section{Identidades explícitas e implícitas; velhas e novas identidades}

57 A defesa de uma alegada neutralidade da sociologia na actual conjuntura inibe e reprime o avanço da ciência paradigmática, como lhe chamou Khun. A ciência normalizada dificilmente pode adaptar as suas práticas científicas às novas necessidades humanas e às novas realidades sociais. Nomeadamente, manter a centralidade das referências normativas à igualdade e à liberdade na sociologia e na sociedade actuais reclama, nesta fase histórica, não apenas oposição à violência institucional - como as perseguições criminais internacionais e também a indução da pobreza e da desorientação de certos grupos nacionais (como os PIGS na Europa) como forma de intimidação dos povos, o que só por si não pode ser feito sob o signo da neutralidade -, mas também a mobilização de críticas à violência humana em geral e ao Holocausto em particular, o que não foi feito pela sociologia, cf. Bauman (1997) e Joas (2005), nem na sequência da obra monumental de Gaston Bouthoul (1991). 

institucionalmente organizada a pretexto de manutenção ou imposição da paz? Eis um problema que não deve continuar a ser evitado pela sociologia, expurgado e espartilhado para a criminologia, a ciência política ou as relações internacionais.

59 A globalização expõe os povos ocidentais a circunstâncias novas, em particular ao levantamento de algumas das barreiras que os defenderam das violências em que viveram outros povos, desde logo aqui ao lado em África. Esta abertura à dureza da vida humana já vivida noutras partes do mundo, o que alguns autores têm chamado as experiências de Sul no Norte, deve ser acompanhada pela sociologia.

Fazer sociologia, nesta perspectiva, é, com certeza, mapear os diferentes recursos das diferentes dimensões sociais - ultimamente mais favoráveis à economia e à política do que à sociedade e à cultura - mas também é reconhecer e medir os desequilíbrios existenciais sentidos por muita gente, seja a nível ideológico seja a nível das simples possibilidades de existência. Fazer sociologia neutral em tempos de risco de derrocada civilizacional representa uma proposta de capitulação em nome de um respeito burocrático pelo lugar institucional da sociologia no concerto das ciências sociais hiperespecializadas.

\section{Da ética artificial e da moral do Estado}

61 É a sociedade e a solidariedade uma coisa boa? Mesmo para os milhões de crianças e velhos que morrem anualmente por falta de acesso a água potável? Serão tais crianças e tais velhos da nossa sociedade? A mesma pergunta se poderá fazer pensando no que ocorre na Grécia nestes últimos meses: a solidariedade da União Europeia contra a Grécia é uma coisa boa?

O mero registo da degradação dos indicadores socioeconómicos e políticos locais não nos dão conta do balanço social correcto. A crise civilizacional não pode ser observada desse modo.

63 As desarmonias local, europeia e global, provocadas por actos políticos punitivos contra certos povos, incluindo Portugal, são acompanhadas pelo obscurecimento do papel das instituições na representação das soberanias em causa. 0 nacionalismo metodológico que tem orientado as diferentes sociologias nacionais, antes ainda de haver uma prática europeia da sociologia, revela-se uma estratégia desadequada ao momento. Falta, por outro lado, uma base de legitimidade europeia suficientemente forte para congregar as diferentes sociologias nacionais.

Falta sobretudo capacidade sociológica para observar os temidos efeitos Lúcifer, a transformação da urbanidade em combates porta-a-porta com os vizinhos. Como falta a capacidade de denunciar os segredos tecnológicos que permitem a instituições poderosas mobilizarem-se contra os povos, como acontece cada vez mais na guerra e aconteceu no Holocausto.

65 Dos sociólogos pode esperar-se mais do que uma tomada de posição defensiva neste debate, nomeadamente contra quem desminta a própria existência da solidariedade social ("there is no such thing as society", Mrs Tatcher dixit). Espera-se investigação e desenvolvimento de competências racionais e emocionais capazes de favorecerem a difusão de novas éticas pan-europeias e globais, pacíficas e humanistas, uma vez identificados e denunciados os seus inimigos. Umas e outras são éticas artificiais,

Forum Sociológico, 21 | 2011 
voluntaristas, variadas, mas que podem ser sujeitas à crítica sociológica em nome de ideais humanitários que sempre caracterizaram a sociologia. Para o que as declarações sobre direitos humanos serão uma referência normativa útil, precisamente na medida em que são ao mesmo tempo altamente abstractas - e idealistas - e radicalmente oponíveis a quotidianos indignos, independentemente das identidades sociais que se construam em cima de tais indignidades.

\section{BIBLIOGRAFIA}

ALEXANDER, M. (2010), The New Jim Crow - Mass Incarceration in the Age of Colorblindness, Nova Iorque, The New Press.

BARBELET, J. (2008), Weber, Passion and Profit, Cambridge, Cambridge University Press.

BATESON, G. (1987), Natureza e Espírito: uma unidade necessária, Lisboa, Dom Quixote.

BAUMAN, Z. ([1989] 1997) Modernidad y Holocausto, Madrid, Sequitur.

BLAU, J. e A. Moncada (2009), Human Rights - a primer, Boulder\&Londres, Paradigm Publishers.

BOLTANSKI, L. (1990), L'Amour et la Justice comme compétences, Paris, Métailié.

BOUDON, R. ([1995] 1998), o Justo e o Verdadeiro - Estudos sobre a Objectividade dos Valores e do Conhecimento, Lisboa, Piaget.

BOUTHOUL, G. ([1961] 1991), Traité de polémologie - Sociologie des guerres, Paris, Payot.

CASTELLS, M. (2003), A Era da Informação: Economia, Sociedade e Cultura em 3 volumes, Lisboa, FCG.

CHERNILO, D. (2006), "Social Theory's Methodological Nationalism: Myth and Reality”, Journal of Social Theory, 9 (1), pp. 5-22.

CHRISTIE, N. (2000), Crime Control as Industry - Towards Gulags, Western Style, Londres, Routledge.

COLLINS, R. (2008), Violence: A Micro-sociological Theory, Princeton, Princeton University Press.

DURKHEIM, É. ([1893] 1984), A Divisão do Trabalho Social, Lisboa, Presença.

DURKHEIM, É. ([1912] 2002), As Formas Elementares da Vida Religiosa, Oeiras, Celta.

ELIAS, N. ([1939] 1990), O Processo Civilizacional (Vols. I e II), Lisboa, Dom Quixote.

FOUCAUlT, M. ([2001] 2004), A Hermenêntica do Sujeito, São Paulo, Martins Fontes.

FUKUYAMA, F. (1996), Confiança - Valores Sociais e Criação de Prosperidade, Lisboa, Gradiva.

GARLAND, D. (2001), The Culture of Control - Crime and Social Order in Contemporary Society, Oxford, Oxford University Press.

GIDDENS, A. (1985), The Nation-State and Violence - Vol II: A Contemporary Critique of Historical Materialism, Cambridge, Polity Press.

JAKOBS, G. e M. C. Meliá (2003), Derecho Penal del Enemigo, Madrid, Cuadernos Civitas. 
JOAS, H. ([2000] 2005), Guerra y Modernidad - estudios sobre la historia de la violencia en el siglo XX, Barcelona, Paidós.

KHUN, T. S., (1970), La structure des révolutions scientifiques, Paris, Flammarion.

LATOUR, B. (2007), Changer de société, refaire de la sociologie, Paris, La Découverte.

MINSKY, M. (1985), The Society of Mind, Londres/NI/Toronto/Sidney, Simon \& Schuster

Paperbacks.

OBORNE, P. (2008), The Triumph of the Political Class, Londres, Pocket Books.

PRETO, J. (2010), Estado Contra Direito - flagrantes do assédio à liberdade de expressão, Lisboa, Argusnauta.

SENNETT, R. (2006), The Culture of the New Capitalism, Yale University Press.

SUPIOT, A. (2002), “Travail, droit et technique”, Droit Social, pp. 13-25.

TARDE, G. (1993), Les Lois de l'Imitation, Paris, Éditions Kimé.

WACQUANT. L. (2002), “From Slavery to Mass Incarceration - Rethinking the «race question» in the US", New Left Review, 13.

WACQUANT, L. (2000), As Prisões da Miséria, Oeiras, Celta.

WIEVIORKA, M. (2005), La Violence, Paris, Hachette Littératures.

WILKINSON, R. e K. Pickett (2009), The Spirit Level - why more equal societies almost always do better, Londres, Penguin.

WOODIWISS, M. (2005), Gangster Capitalism: The United States and the Global Rise of Organized Crime, Londres, Constable \& Robinson.

YOUNG, J. (1999), The Exclusive Society, Londres, Sage.

ZIMBARDO, P. (2007), The Lucifer Effect: understanding how good people turn evil, Nova Iorque, Random House.

\section{NOTAS}

1. Sobre a questão, ler, por exemplo, Daniel Chernilo (2006).

2. Bernard Lahire anunciou ir publicar um livro, no primeiro semestre de 2012 , sobre como a organização da produção da sociologia, como ciência, resultou no autocentramento ultraespecializado e cognitivamente inócuo.

3. "Neoliberalism is one logic in the world today; human rights is the other", Blau e Moncada (2009:15).

4. $55 \%$ dos afro-americanos de Chicago não podem votar mais na vida por terem cometidos crimes. Na Califórnia há 12 vezes mais afro-americanos presos por posse de marijuana do que brancos. Ver outros números, por exemplo, em http://www.drugwarfacts.org/cms/node/64.

5. Estimativas divulgadas por Manuel Almeida dos Santos, visitador de décadas das prisões portuguesas e ex-presidente da sessão portuguesa da Amnistia Internacional.

6. Estimativa apontada por um recluso, confirmada como verosímil por vários guardas prisionais.

7. Uma lei do final de 2011 nos EUA incluiu os próprios cidadãos norte-americanos alvos potenciais enquanto inimigos. Podem ser presos pelas forças armadas sem direito a nenhum recurso legal.

8. Explicitamente é esse o caso de Wieviorka (2005) e implicitamente de Collins (2008). 
9. As discussões sobre o sentido da justiça, em Boltanski (1990) e em Boudon (1998), por exemplo, mostram como a sociologia tem uma ampla margem de desenvolvimento para percorrer neste campo.

10. Adaptation (economia) Goal Attainment (política) Integration (sociedade) Latency (cultura).

11. Sobre o caso português, ler Preto (2010).

12. Cf. http://www.icdc.com/ paulwolf/cointelpro/churchfinalreportIIIc.htm.

13. Cf. http://www.dn.pt/inicio/portugal/interior.aspx?content_id=2131659.

\section{RESUMOS}

A crise civilizacional que se sente estarmos a viver ainda não está a ser acompanhada por um questionamento moral que é de esperar vir a ocorrer, no quadro de um processo de transformação mais vivo e abrangente do que aquele que hoje já vivemos. Este artigo procura abrir brechas para os debates que irão emergir, procurando encontrar formas racionais de articular as mudanças sociais em curso e as mudanças necessárias à actualização da teoria social.

The civilization crisis one is living these days is not yet followed by a moral explicit questioning. Moral questioning is expected to happen one day when the social transformation process do become more intense and general than today. This paper shows emerging angles of debate. It tries to merge social change, and social theory, in a rational manner looking forward to more harmony between what sociology says and real life experiences.

\section{ÍNDICE}

Keywords: ethics, morals, State, social theory

Palavras-chave: ética, moral, Estado, teoria social

\section{AUTOR}

\section{ANTÓNIO PEDRO DORES}

Professor no Departamento de Sociologia do ISCTE-IUL e investigador no Centro de Investigação e Estudos de Sociologia ISCTE-IUL

antonio.dores@iscte.pt 